\title{
Population dynamics and spatial distribution of Griffon Vultures (Gyps fulvus) in Portugal
}

FLORIS VAN BEEST, LOES VAN DEN BREMER, WILLEM F. DE BOER, IGNAS M. A. HEITKÖNIG and ANTÓNIO E. MONTEIRO

\section{Summary}

The global decrease of vulture populations has been attributed to several factors, such as food availability, poisoning, human disturbance, or habitat suitability. We studied the effect of factors that vary both spatially and temporally on the nest site distribution of the Griffon Vulture Gyps fulvus in northeast Portugal, and influence the population dynamics of these cliff-dwelling birds. Several demographic parameters were studied in the field, and the age structure of the population was determined. Additionally we investigated how food availability affected population fluctuations. The vulture population was most sensitive to juvenile mortality according to our model results. Our models showed that a decrease in the present food supply resulted in a decrease in vulture abundance and, moreover, negatively affected the spatial distribution of the species by decreasing the number of breeding pairs per colony. The total quantity of sheep and goat biomass, a greater distance to the nearest unpaved road, and the presence of Egyptian Vultures Neophron percnopterus at the breeding colonies showed a significant positive relationship to the numbers of Griffon Vulture breeding pairs. It is recommended that the available food supply in the most important foraging areas should be monitored and protected. Furthermore, to manage the community of cliff breeding raptors adequately, future research should identify and protect the most suitable breeding areas for each species. Human disturbance should be kept to a minimum by protecting breeding areas, especially in an area like Riba-Côa where species such as the Egyptian Vulture, Bonelli's Eagle Hieraaetus fasciatus and Griffon Vulture breed so close to each other.

\section{Introduction}

Vultures are seriously threatened in Europe (Tucker and Heath 1994, Donázar et al. 2002a, BirdLife International 2007), the Middle East (Newton and Newton 1996), Asia (Green 2006, Green et al. 2006), and Africa (Thiollay 2006). Some studies have highlighted the importance of factors such as human disturbance (Gavashelishvili et al. 2006), poisoning (Donázar et al. 2002a, Green 2006), or food availability (Thiollay 2006). However, other studies (Donázar et al. 2002b, Parra and Tellería 2004, Poirazidis et al. 2004, Monadjem and Garcelon 2005; Gavashelishvili et al. 2006, Moran-Lopez et al. 2006) focused on the importance of factors that varied spatially, affecting nest site selection and local breeding success. There is therefore an urgent need to analyze the effect of factors that vary spatially, as well as temporally in relation to their effects on vulture populations.

The global population status of the Griffon Vulture Gyps fulvus Hablizl, 1783, has not been quantified accurately, but the species is not believed to approach the thresholds for the population decline criterion of the IUCN Red List. The current status of the species is therefore evaluated as "Least Concern" (BirdLife International 2007). Nevertheless, the Griffon Vulture is extinct in many parts of its former distribution (Slotta-Bachmayr et al. 2004). The main threats 
to the viability of Griffon Vulture populations are similar throughout their range (Donázar and Fernández 1990). Food abundance especially is considered an essential factor in the population dynamics of vultures (Parra and Tellera 2004, Thiollay 2006). For instance, Parra and Tellería (2004) found a functional relationship between food availability and vulture abundance; the number of vultures was greater in areas with higher food availability, whilst other studies confirmed the importance of food availability affecting population growth over time (Donázar and Fernández 1990). Suitable habitat for nesting places (Ruxton and Houston 2002) is an important variable, often linked to differences in colony size, influencing population growth (Parra and Tellera 2004). However, the Griffon Vulture populations in Iberia appear to be healthy (Dónazar and Fernández 1990). The Riba-Côa area in northeast Portugal is one of the most important regions in the country for cliff breeding birds, and Griffon Vultures appear to have a stable breeding population (A.E. Monteiro, pers. obs.).

This study examines the population dynamics of Griffon Vultures in the Riba-Côa area by constructing a simple mathematical model with the support of available census data. The main objectives of this study are: 1 ) to examine the population dynamics of the Griffon Vulture and to test whether food availability affects population fluctuations over time, and 2) to investigate which variables determine nest site selection, and how these variables explain the spatial distribution of Griffon Vultures.

\section{Methods}

\section{Study area}

Fieldwork was carried out between June and October 2005 in northeast Portugal, in the Riba-Côa area, and part of the Parque Natural do Douro Internacional (centre $41^{\circ} 14^{\prime} \mathrm{N}, 6^{\circ} 41^{\prime} \mathrm{W}$ ). The river valley forms the border with Spain and includes several river canyons. The main rivers are the Douro (national and international sections), the Águeda (international section) and the Côa. The total length of these valleys is $115 \mathrm{~km}$. The area has a mean annual temperature of $15-20^{\circ} \mathrm{C}$ and an annual rainfall of $c .1300 \mathrm{~mm}$. As a result of the inaccessibility and remoteness of the area and the large availability of cliffs along the sides of the main valleys, the area holds approximately 365 pairs of Griffon Vultures and approximately 150 pairs of Egyptian Vultures (A. Berliner, pers. comm.). Moreover it is a vital breeding area for Bonelli's Eagle Hieraaetus fasciatus with $c$. nine breeding pairs (approximately 10\% of the national population), Golden Eagle Aquila chrysaetos with c. 29 pairs, and Black Stork Ciconia nigra with c. 17 pairs (A.E. Monteiro, pers. obs.).

\section{Population modelling}

To study the population dynamics and the role of food availability on the Griffon Vultures in Riba-Côa we constructed a model based on several demographic parameters (e.g. mortality and reproduction) and the age structure of the population. To evaluate fluctuations in breeding pairs over time and to calculate productivity we used census data from 1996 to 2005 . To quantify the age structure we selected 15 breeding colonies (with one observation site per colony) where we counted and classified all visible Griffon Vultures into four age classes (juveniles: < 1yr, immatures: $1-2 \mathrm{yr}$, sub-adults: $3-4 \mathrm{yr}$, or adults: $\geqslant 5 \mathrm{yr}$ ) according to their physical characteristics (Elosegi 1989). The selection of observation sites was based on the number of birds present within the colony, as it was crucial to classify as many birds as possible. All sites were visited on rainless days with good light and visibility. Each site was visited three times (once every month), either in the morning (o6hoo-1ohoo) or late afternoon (17hoo-21hoo), depending on light conditions. All observations were made by telescope from a distance $(>100 \mathrm{~m})$ to minimize disturbance. 


\section{Spatial distribution}

To study habitat preferences and consequently analyze which factors determine Griffon Vulture distribution, an intensive literature study was conducted to extract the most important variables. Studies on Griffon Vultures are rare, and therefore also findings and estimates from studies carried out on other vulture species were used for this part of the analysis as well as for the population modelling. In total 23 potential variables were identified concerning geography, disturbance, food availability, and intra- and interspecific relations. These variables were measured at the 15 observation sites and in 15 additional sites where Griffon Vulture numbers used to be high, but are now low or birds are absent. Variables were mainly measured with the aid of Arc View 3.1, using data derived from topographic maps (IGEOE 2000) and aerial photography (CNIG 2003). Information about other raptor species (number of breeding pairs in 2005) was supplied by the Instituto da Conservação da Natureza.

The geographic variables measured were 'cliff slope' (of the observation site) and the 'altitudinal difference'. The altitudinal difference (m) was measured by taking the average of the height difference from the top to the bottom of the three steepest places at each observation site. Additionally, the slope of these three steepest places was calculated and averaged.

Variables concerning human disturbance included: 'distance to nearest paved road', '- nearest unpaved road', '- nearest village' and '- nearest power line' $(\mathrm{km})$. These distances were measured from the centre of each breeding colony (observation site). Unfortunately we were unable to analyze the effect of these variables with regard to the distance to the colony edge, as it was extremely difficult to determine where the exact boundaries of the colonies were. Therefore, all measurements were taken from the centre of the colony, which was the location with the highest concentration of nests. Furthermore, the total length $(\mathrm{km})$ of the above mentioned infrastructures situated within a $500 \mathrm{~m}$ radius around the observation sites was measured. The total surface area $\left(\mathrm{m}^{2}\right)$ of different land use types (olive groves, vineyards and cereal fields) within a $500 \mathrm{~m}$ radius was also measured, since some land use types are more intensively cultivated than others and can create more disturbance. Lastly, the human density was calculated within a $25 \mathrm{~km}$ radius circle around the observation sites (2001 data supplied by Instituto Nacional de Estatística Portugal).

To measure food availability all livestock biomass present in a $25 \mathrm{~km}$ radius from the centre of each observation site was calculated. Arroyo and Garza (1995) showed that the foraging area of Griffon Vultures is not a perfect circle around a breeding site. Moreover, they showed that $70 \%$ of the Griffon Vulture records, while foraging, were made $<25 \mathrm{~km}$ away from the corresponding colonies. Livestock biomass present in a $25 \mathrm{~km}$ radius was calculated using 1999 census data (Instituto Nacional de Estatística Portugal). Cows, sheep and goats represent the major food source for vultures in the area (Parra and Tellaría 2004). To calculate the available meat biomass available to vultures, first the number of animals that died per year was calculated ( $1 \%$ of all cattle per year and $2.5 \%$ of all sheep/goats per year; Bort et al. 1993). The number of dead animals from each species was multiplied by a standard body weight ( $550 \mathrm{~kg}$ for cattle, $55 \mathrm{~kg}$ for sheep and goats; Parra and Tellería 2004). Next, the standard body weight was multiplied by a conversion factor of 0.66 , to correct for the weight of young animals (S. van Wieren pers. comm.). Griffon Vultures eat only meat, organs and intestines (Mundy et al. 1992), so the potential available biomass available to vultures is $31 \%$ of the total body weight for cattle (Friedman and Mundy 1983) and $27 \%$ for sheep and goats (Donázar and Fernández 1990). The total available 'food biomass' (cattle plus sheep and goat) was also used as an explanatory variable in the analysis.

Variables concerning intraspecific relationships included: 'distance to nearest occupied cliff' (by Griffon Vultures) and 'number of Griffon Vulture breeding pairs in a $2 \mathrm{~km}$ radius around each site'. Variables concerning the interspecific relationships included: 'distance to nearest Egyptian Vulture nest', '- Bonelli's Eagle nest' and '- Golden Eagle nest' in km. Besides this, the numbers of nests from these three species were counted within a $500 \mathrm{~m}$ radius circle around the selected sites. 
The different radii used in this study for the different variables were similar to the ones used for studying Griffon Vultures in Arroyo and Garza (1995) and, moreover, ensured a full dataset, avoiding zero counts. For instance, livestock or human densities could not be calculated reliably when using a radius of only 50om, and are probably more important at a larger spatial scale.

\section{Analyses}

The population age structure was calculated from the proportion and the total number of birds present in the four age classes. We also calculated several demographic parameters. The average annual productivity used in this study was calculated according to Cheylan (1981):

$$
\text { Productivity }=\frac{N^{\circ} \text { of fledgling young }}{N^{\circ} \text { of breeding pairs }}
$$

We estimated annual mortality rates (AMR) by calculating the number of birds in one age class (A) that failed to move into the subsequent age class (B), using the formula:

$$
\text { Annual Mortality Rate }=\frac{\left(N^{\circ} \text { of birds class } A-N^{\circ} \text { of birds class } B\right)}{\left(N^{\circ} \text { of birds class } A / 100\right)}
$$

Only the mortality rates of juveniles and immatures were calculated this way. Immature and sub-adult birds remain in their own age class for two years before progressing to the subsequent age class (Elosegi 1989). Therefore we created two subgroups of immatures $\left(1^{\text {st }}\right.$ and $2^{\text {nd }}$ year immatures), each with their own AMR and two subgroups of sub-adults $\left(1^{\text {st }}\right.$ and $2^{\text {nd }}$ year subadults). Mortality rates for sub-adult and adult birds were estimated using the model. To our knowledge there is no information available concerning egg and hatchling mortality of Griffon Vultures. Therefore, the productivity parameter in combination with information on the breeding biology of Lappet-faced Vultures Torgos tracheliotus (Newton and Newton 1996) was used to estimate the different mortality factors. To do so we calculated the number of nests that is necessary to sustain the present population.

$$
N^{\circ} \text { of active nests }=\frac{N^{\circ} \text { of Juveniles }}{\text { Productivity }}
$$

Furthermore, we calculated the proportion of the adult population that is actively involved in the breeding process.

$$
\% \text { breeding adults }=\left(\frac{N^{\circ} \text { of active nests } * 2}{N^{\circ} \text { of adults }}\right) * 100
$$

To incorporate food availability into the model we calculated the quantity of food required for the population in order for it to survive. We estimated that all birds, except juveniles, eat on average $164.25 \mathrm{~kg}$ of meat per year (450 g of meat per day in reported in Mendelssohn and Leshem 1983, Donázar and Fernández 1990 for other Griffon Vulture populations). Juveniles require an average of $320 \mathrm{~g} / \mathrm{d}$ (Donázar and Fernández 1990) until they are able to forage for themselves and have permanently left the nest after about 210 days (Mundy et al. 1992). After this they require $450 \mathrm{~g} / \mathrm{d}$, which results in an average of $137 \mathrm{~kg}$ per year. These amounts fall within the range reported by Komen (1991) for hand-rearing nestlings of the larger Cape Griffon Gyps coprotheres, with 791g/d during the period of maximum growth.

The population model was built in Stella (Dynamic modelling software; Version 8.o for Windows 2003). We had to make several assumptions: 
- Breeding is restricted to adult birds only (for Griffon Vultures: Blanco et al. 1997, Cape Griffon: Borello and Borello 2002).

- Migration is not included since no accurate data are available for this species.

- For simplicity and lack of data we assumed that the natural mortality and reproduction rates are similar in each consecutive year (but see Borello and Borello 2002 for Cape Griffon).

- Food requirement (in $\mathrm{kg} / \mathrm{yr}$ ) is assumed to be similar for adults, sub-adults and immatures, since body size between age-classes does not vary much.

- No direct mortality due to food shortage was included as there were no figures available concerning mortality and the different mortality causes.

- According to Slotta-Bachmayr et al. (2004) Griffon Vulture breeding success varies in accordance with food availability. We therefore made the percentage of breeding adults dependent on food supply such that in a period of food shortage the number of breeding adults will decrease linearly. When there is no food limitation the number of breeding adults becomes dependent on the number of adults.

A schematic representation of the model is given in Figure 1. All simulations were run for 100 years unless otherwise indicated. A sensitivity analysis was performed to identify the parameters to which the population reacts strongly. The analysis was performed by running the model with the default settings, after which the model was run again while the value of one parameter was increased and then decreased by $20 \%$. The influence of the tested variable was calculated from the average percentage of change in the total population size resulting from the test runs compared to the default run. This process was repeated for all parameters in the model.

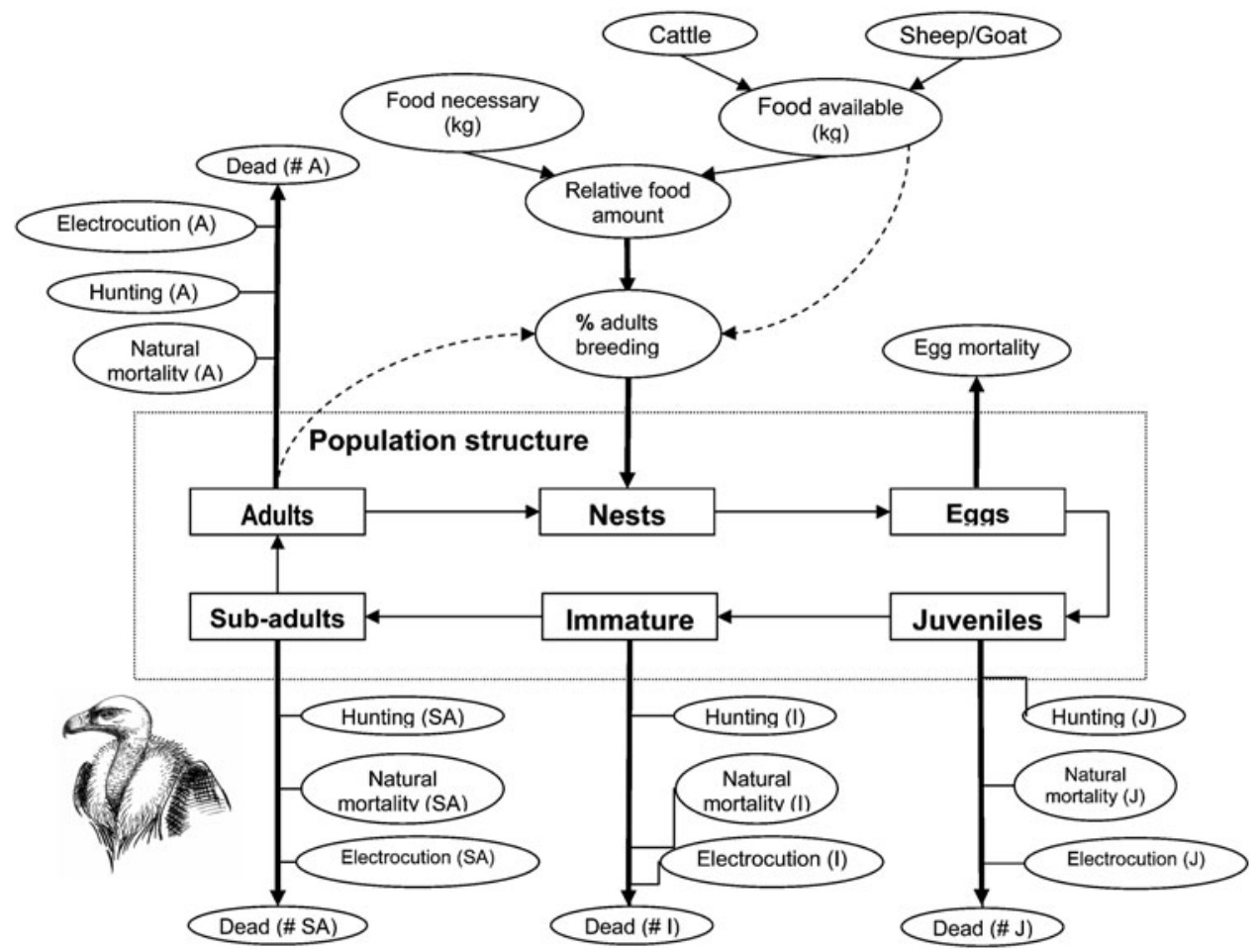

Figure 1. Conceptual design of the Griffon Vulture population model with the impact of food availability on breeding adults. 
Analysis of the spatial distribution data was carried out using the statistical software package SPSS v. 12. Several steps were taken to extract the most important variables that could explain the spatial distribution of Griffon Vultures. Variables that showed significant differences between occupied and non-occupied sites were directly included in further analyses. From the remaining variables, when two variables were similar (for example, total length of paved roads and distance to nearest paved road), only the normally distributed variables were included. To analyze the relationship between the number of breeding pairs and the environmental variables, only data from the occupied cliffs were used, using 'number of breeding pairs in a $2 \mathrm{~km}$ radius' as the dependent variable, which followed a normal distribution. The remaining predictor variables were checked for multicollinearity with the use of a correlation matrix. When two variables correlated significantly, one of them was excluded from the model, and priority was given to variables that had shown a significant relationship with vulture occurrence in similar studies. With the remaining set of variables, a backward multiple linear regression was carried out and those that did not contribute significantly to the model were removed. Simultaneously the variance inflation factors (VIF) were calculated, which indicate the more subtle forms of collinearity. We selected the final model based on the VIF (Field 2005), and the highest $\mathrm{R}^{2}$ Adjusted.

\section{Results}

Population modelling - Calculation of demographic parameters.

Analyzing the census data for the period 1996 to 2005 (Fig. 2), resulted in an average number of breeding pairs of 343 (SD. \pm 35.7 ), producing an average of 238 juveniles/yr (SD. \pm 36.7 ). This yielded an average annual productivity of 0.69 juveniles per breeding pair (SD \pm 0.07 ). In total 1863 birds were observed in the field (including double counts) and classified into their appropriate age class. However, the first month of observations produced a biased picture of the population's age distribution: a relatively low number of adults was observed when compared to the number of juveniles ( $\mathrm{N}^{\circ}$ of juveniles $>50 \%$ of adults). To minimize errors in observation bias we therefore calculated the age structure using only the data of the last two months when number of juveniles $<50 \%$ of adults. Using this approach the total population was approximately 1,306 birds, and the juveniles constituted about $18.2 \%$ of the total population (Table 1).

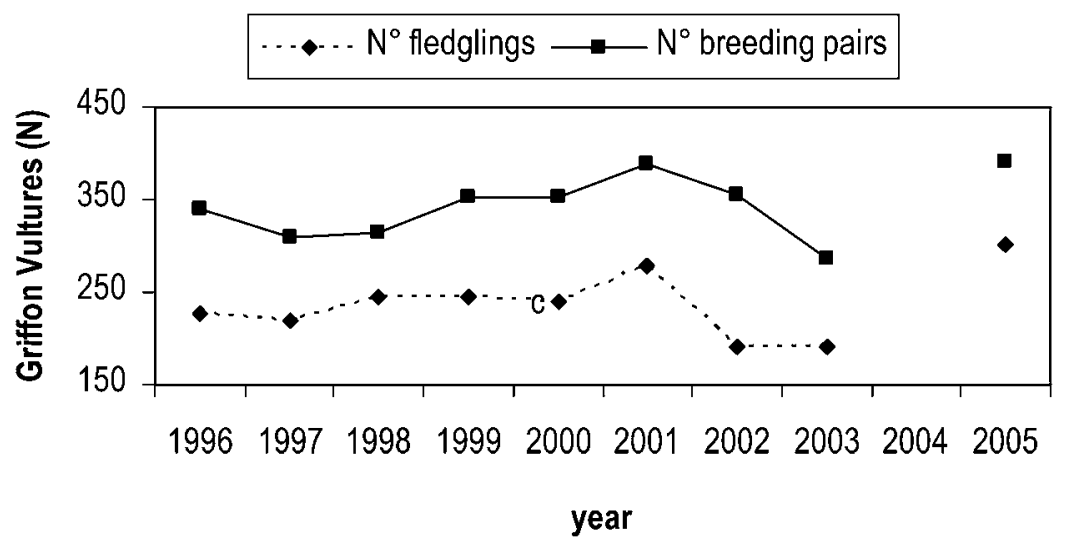

Figure 2. Census data for the Griffon Vulture population in Riba-Côa, north-eastern Portugal, between 1996 and 2005 . 
Table 1. Age structure of the Griffon Vulture population in the Riba-Côa area, 2005.

\begin{tabular}{lcc}
\hline Age class & \% of population & $\mathbf{N}^{\circ}$ of birds in population \\
\hline Adults & 67.9 & 887 \\
Sub-adults & 6.3 & 82 \\
Immatures & 7.6 & 99 \\
Juveniles & 18.2 & 238 \\
Total & 100 & 1306 \\
\hline
\end{tabular}

With 238 juveniles present in the population and an average annual productivity of 0.69 there should, on average, be $c .345$ nests and consequently c. 690 adult birds actively breeding. This indicates that the proportion of breeding adults is $77.7 \%$ of the total number of adult birds.

Using data from Lappet-faced Vulture and educated guesses it was estimated that $90 \%$ of the breeding pairs actually produced an egg after nest building, that egg mortality was $11 \%$ and hatchling mortality $14 \%$. The AMR for juveniles was calculated to be $(237.66-55) /(237.66 /$ 100 $)=76.9 \%$. For immature birds two different AMR were calculated: $(55-44) /(55 / 100)=$ $20 \%$ for $1^{\text {st }}$ year immatures, and $(44-42) /(44 / 100)=4.5 \%$ for $2^{\text {nd }}$ year immatures.

The total amount of livestock biomass available for the vulture population in the Riba-Côa area is $260,600 \mathrm{~kg} / \mathrm{yr}$. According to our calculations, a population of approximately 1,306 birds with an age structure distribution equivalent to the Riba-Côa population would require $80 \%$ of this amount to fulfil its food requirements (Table 2).

\section{Population model}

With the population dynamics model we started by making an assessment of the AMR for the sub-adults and adults. Because census data showed a stable population over the years we had to estimate a mortality rate that would reflect this trend. Ultimately, an AMR of 0.04 and 0.045 for adults and sub-adults, respectively, provided a stable population over time (Fig. 3).

After incorporating food availability into the model we tested its effect on population numbers by creating a situation with several years of food shortage. Food shortage started in year 15 and ended in year 20. During this time the available food biomass for the vultures was reduced by $50 \%$. Food scarcity resulted in a population drop of $11 \%(n=1,170$ in $\operatorname{yr} 15$ to $n=1,038$ in year 20; Fig. 4). Due to fewer adult birds breeding (59\% of adult population in year 18 ), the number of juveniles decreased by $25 \%$ during these 5 years. Fewer juveniles resulted in a lower recruitment into the subsequent age classes, with at the end a $7 \%$ drop in adult birds. The effect of the reduced recruitment rate, and therefore the subsequent smaller adult class some years later changes the population structure over several decades. After food biomass returned to its original quantity more adult pairs came to breed ( $84 \%$ of adult population), which resulted in an increase in the number of juveniles. The number of adults at the end of the simulation (100 years) was still $2 \%$ smaller than at the beginning of the simulation when food was not limiting the breeding performance.

Table 2. Food requirement of the Griffon Vulture population in the Riba-Côa area.

\begin{tabular}{lllcc}
\hline Age class & $\mathbf{k g} /$ day & $\mathbf{k g} /$ year & $\mathbf{N}^{\circ}$ of birds & biomass (kg / yr) \\
\hline Adults & 0.45 & 164.25 & 887 & 145,690 \\
Sub-adults & 0.45 & 164.25 & 82 & 13,469 \\
Immatures & 0.45 & 164.25 & 99 & 16,261 \\
Juveniles & 0.37 & 136.75 & 238 & 32,547 \\
Total & & & & 207,966 \\
\hline
\end{tabular}




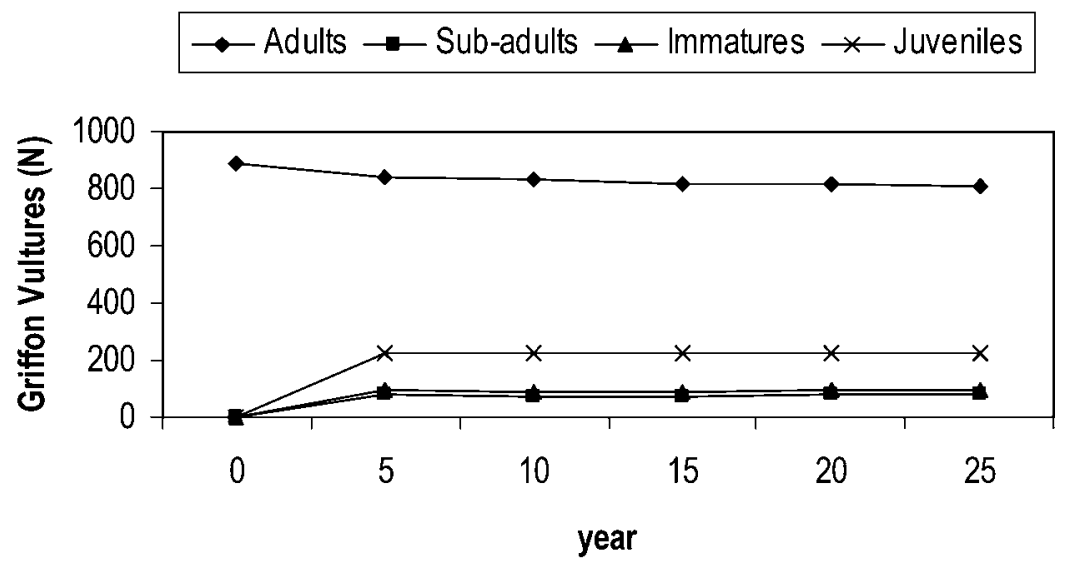

Figure 3. Predicted fluctuations of the Griffon Vulture population over time (25 years). Annual mortality rate for adult birds $=0.04$ and for sub-adults $=0.045$.

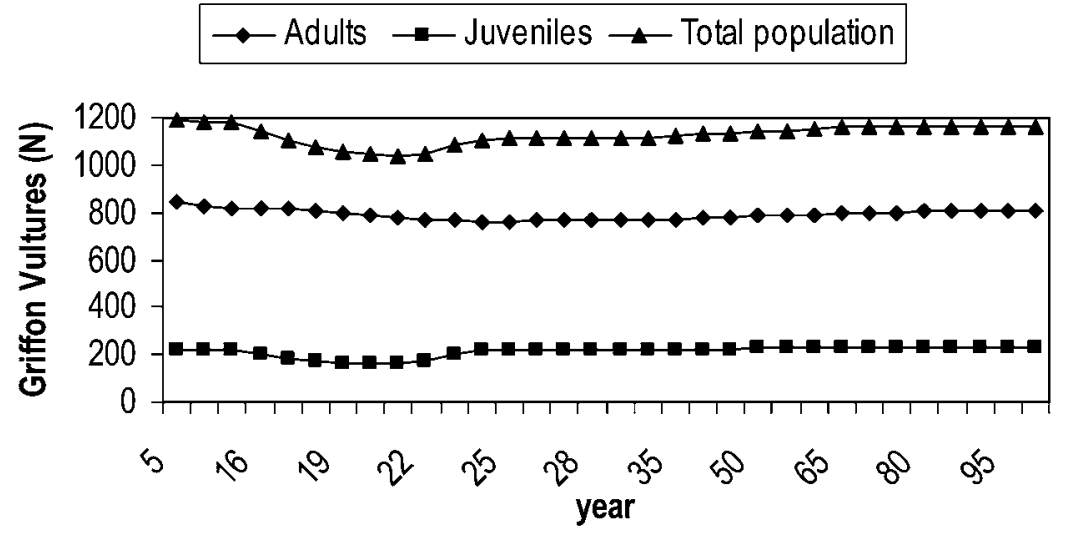

Figure 4. Predicted Griffon Vulture population fluctuations, adults and juveniles, in response to a 5 -year period of food scarcity, in which food biomass was reduced by $50 \%$ during years 15 to 20.

The sensitivity analysis (Table 3) showed that changes in the natural mortality of juvenile birds resulted in the greatest fluctuations in total population size. With an increased mortality rate of $20 \%$ for juvenile birds the vulture population decreased to 564 birds. A decreased mortality rate of $20 \%$ resulted in an expansion of the population to 1993 birds. This is a mean difference of $48 \%$. Mortality rates altered in a similar way for adult birds resulted in a mean difference in total population size of only 10\% while similarly altered hatchling and egg survival resulted in mean differences of $15 \%$.

\section{Spatial distribution}

For five of the 23 variables significant differences were found when comparing occupied with non-occupied sites, namely: distance to the nearest occupied cliff, cliff slope, sheep and goat biomass within a $25 \mathrm{~km}$ radius, distance to nearest village and human density in a $25 \mathrm{~km}$ radius (Table 4). This univariate analysis indicates factors that can explain the difference in nest 
Table 3. Results from the sensitivity analysis with the column 'Rate (\%)' showing the values with a $20 \%$ decrease and $20 \%$ increase, and their subsequent effect on the size of the total population, together with the mean effect $(\%)$ calculated from the comparison with the default run.

\begin{tabular}{|c|c|c|c|}
\hline Parameter & Rate (\%) & Total population $(N)$ & Mean difference (\%) \\
\hline \multirow[t]{2}{*}{ Adult mortality } & 0.032 & 1,373 & 10 \\
\hline & 0.048 & 1,032 & \\
\hline \multirow[t]{2}{*}{ Sub-adult 2 mortality } & 0.036 & 1,167 & $<_{1}$ \\
\hline & 0.054 & 1,164 & \\
\hline \multirow[t]{2}{*}{ Sub-adult I Mortality } & 0.036 & 1,167 & $<1$ \\
\hline & 0.054 & 1,163 & \\
\hline \multirow[t]{2}{*}{ Immature 2 mortality } & 0.036 & 1,168 & $<1$ \\
\hline & 0.054 & 1,163 & \\
\hline \multirow[t]{2}{*}{ Immature 1 mortality } & 0.16 & 1,197 & 2 \\
\hline & 0.24 & 1,145 & \\
\hline \multirow[t]{2}{*}{ Juvenile mortality } & 0.615 & 1,993 & 48 \\
\hline & 0.923 & 564 & \\
\hline \multirow[t]{2}{*}{ Hatchling survival } & 0.688 & 949 & 15 \\
\hline & 1.032 & 1,457 & \\
\hline \multirow[t]{2}{*}{ Egg survival } & 0.712 & 949 & 15 \\
\hline & 1.068 & 1,457 & \\
\hline
\end{tabular}

densities between the colonies. However, non-significant factors can still be important in a multiple regression, but the analysis is hampered by collinearity between independent factors. In order to build a good regression model we calculated a correlation matrix and omitted variables from the model with large VIF values. A total of 16 variables were included in the Spearman correlation matrix. The following variables were removed from further analysis, because they correlated highly with other variables: 'distance to nearest occupied cliff', 'distance to nearest village', 'distance to nearest paved road', 'human density', 'altitudinal difference', 'olive grove $500 \mathrm{~m}$ radius', 'vineyard $500 \mathrm{~m}$ radius' and 'cereal field within $500 \mathrm{~m}$ radius'. After carrying out a multiple linear regression and checking for co-linearity the following variables were removed: 'cliff slope' and 'distance to nearest Golden Eagle nest'. The remaining model has an $R_{\text {adj }}^{2}$ of 0.443 , which means that $44 \%$ of the variability in the number of breeding pairs is accounted for by this set of explanatory variables (Table 5). One observation site contained a much higher number of breeding pairs than the other sites, which does not seem to be explained by the variables measured. Possibly the dependent variable is influenced by another (more important) predictor variable that we failed to measure in the field. The outlier was removed from the analysis to see if this increased the explanatory power of the model. This resulted in model 2 (Table 5) with an $R_{\text {adj }}^{2}$ of 0.804 . The contribution of each explanatory variable to the $R_{\text {adj }}^{2}$ was calculated by removing every single variable separately from the linear regression analysis and calculating the change in the $R_{\text {adj }}^{2}\left(\Delta R_{\text {adj, }}^{2}\right.$ Table 5). In both models sheep and goat biomass accounted for the largest part of the variance. The variables 'distance to the nearest Bonelli's Eagle nest' and 'distance to the nearest Egyptian Vulture nest' negatively affected the number of Griffon Vulture breeding pairs and also accounted for a large part of the explained variance (Table 5). Surprisingly, the correlation with the distance to power lines was negative, indicating a higher density of breeding pairs near power lines.

\section{Discussion}

Using the Griffon Vulture population in the Riba-Côa area as an example, we showed the potential effect of several factors that varied spatially or temporally, on population change. The population appears to be stable. Census data acquired between 1996 and 2005 showed some 
Table 4. Mean values (standard deviation) of environmental variables at occupied and non-occupied sites. Test statistic $(t$ or $U)$ and significance level $(P)$ for group differences are given.

\begin{tabular}{|c|c|c|c|c|c|c|}
\hline Variable & Unit & occupied $(\mathrm{N}=15)$ & non-occupied $(N=15)$ & Test & $\begin{array}{l}\text { Test statistic } \\
\text { (t or } U \text { ) }\end{array}$ & $P$ \\
\hline Distance to nearest occupied cliff & $\mathrm{km}$ & $0.73(0.73)$ & $3.7(3.4)$ & t-test & -3.30 & 0.003 \\
\hline Clif slope & & $1.62(0.5)$ & $2.36(0.71)$ & t-test & -3.28 & 0.003 \\
\hline Altitudinal difference & $\mathrm{m}$ & $85.8(44.6)$ & $67.1(26.2)$ & t-test & 1.18 & 0.247 \\
\hline Nearest unpaved road & $\mathrm{km}$ & $0.43(0.22)$ & $0.32(0.17)$ & t-test & 1.59 & 0.123 \\
\hline Nearest paved road & $\mathrm{km}$ & $2.37(1.53)$ & $1.6(1.11)$ & t-test & 0.144 & 0.163 \\
\hline Nearest power line & $\mathrm{km}$ & $2.88(1.8)$ & $1.89(1.15)$ & t-test & 1.28 & 0.214 \\
\hline Nearest village & $\mathrm{km}$ & $2.95(0.86)$ & $1.82(1.14)$ & t-test & $3 \cdot 41$ & 0.002 \\
\hline Total length unpaved roads & $\mathrm{km} / 500 \mathrm{~m}$ radius & $0.86(1.1)$ & $0.94(0.53)$ & Mann-Whitney U & 90 & 0.367 \\
\hline Total length paved roads & $\mathrm{km} / 500 \mathrm{~m}$ radius & o & $0.09(0.26)$ & Mann-Whitney U & $97 \cdot 5$ & 0.539 \\
\hline Total length power lines & $\mathrm{km} / 500 \mathrm{~m}$ radius & $0.17(0.46)$ & o & Mann-Whitney U & $97 \cdot 5$ & 0.539 \\
\hline Human density & $\mathrm{N} / 25 \mathrm{~km}$ radius & $26,277(5,381)$ & $23,291(2,524)$ & Mann-Whitney U & 53 & 0.013 \\
\hline Cows & $\mathrm{kg} / 25 \mathrm{~km}$ radius & $35,394(11,259)$ & $32,989(7,104)$ & t-test & 0.7 & 0.490 \\
\hline Sheep \& goat & $\mathrm{kg} / 25 \mathrm{~km}$ radius & $33,607(7,450)$ & $42,031(2,137)$ & Mann-Whitney U & 28 & 0.001 \\
\hline Total food biomass & $\mathrm{kg} / 25 \mathrm{~km}$ radius & $72,592(19,226)$ & $74,233(6,885)$ & Mann-Whitney U & 104 & 0.724 \\
\hline Nearest Egyptian Vulture nest & $\mathrm{km}$ & $0.44(0.63)$ & $0.33(0.29)$ & t-test & 0.24 & 0.813 \\
\hline Nearest Bonelli Eagle nest & $\mathrm{km}$ & $1.98(1.5)$ & $3.39(3.16)$ & t-test & -1.56 & 0.135 \\
\hline Nearest Golden Eagle nest & $\mathrm{km}$ & $0.75(0.82)$ & $1.02(1.01)$ & t-test & -1.02 & 0.318 \\
\hline Number Bonelli Eagle nest & $\mathrm{N} / 5$ oom radius & $0.27(0.59)$ & $0.6(1.30$ & Mann-Whitney U & 109 & 0.812 \\
\hline Number Golden Eagle nest & $\mathrm{N} / 500 \mathrm{~m}$ radius & $0.6(0.63)$ & $0.6(0.91)$ & Mann-Whitney U & 104 & 0.676 \\
\hline Number Egyptian vulture nest & $\mathrm{N} / 5$ oom radius & $1(1.25)$ & $0.93(0.590$ & Mann-Whitney U & 101 & 0.569 \\
\hline Olive-yards & $\mathrm{m}^{2} / 500 \mathrm{~m}$ radius & $34,470(56,377)$ & $12,855(17,752)$ & t-test & 1.37 & 0.190 \\
\hline Vine-yards & $\mathrm{m}^{2} / 500 \mathrm{~m}$ radius & $10,490(22,867)$ & $13,131(25,593)$ & t-test & -0.29 & 0.772 \\
\hline Cereal & $\mathrm{m}^{2} / 500 \mathrm{~m}$ radius & $3,906(10,861)$ & $1,934(6,065)$ & t-test & 0.61 & 0.548 \\
\hline
\end{tabular}


Table 5. Regression coefficients given for model 1 (outlier included) and model 2 (outlier excluded), with pvalues, $\mathrm{R}^{2}$ adjusted and $\Delta \mathrm{R}^{2}$ adjusted.

\begin{tabular}{|c|c|c|c|c|c|c|}
\hline Variables & Model 1 & $P$ & $\begin{array}{l}\Delta R^{2} \\
\text { adjusted }\end{array}$ & Model 2 & $P$ & $\begin{array}{l}\Delta \mathrm{R}^{2} \\
\text { adjusted }\end{array}$ \\
\hline (constant) & -101 & 0.053 & & 0.352 & 0.983 & \\
\hline Cow biomass & 0.001 & 0.083 & 0.182 & & & \\
\hline Sheep/goat biomass & 0.004 & 0.017 & 0.497 & 0.002 & 0.002 & 0.543 \\
\hline $\begin{array}{l}\text { Distance to nearest unpaved } \\
\text { road }\end{array}$ & 139 & 0.017 & 0.492 & 48.460 & 0.007 & 0.331 \\
\hline Cliff slope & & & & -7.130 & 0.288 & 0.008 \\
\hline Distance to nearest powerline & -13.8 & 0.070 & 0.208 & & & \\
\hline $\begin{array}{l}\text { Distance to nearest Bonelli's } \\
\text { Eagle nest }\end{array}$ & -15.1 & 0.073 & 0.203 & -14.550 & 0.001 & 0.672 \\
\hline $\begin{array}{l}\text { Distance to nearest Egyptian } \\
\text { Vulture nest }\end{array}$ & $-39 \cdot 3$ & 0.024 & 0.420 & -20.990 & 0.012 & 0.225 \\
\hline $\begin{array}{l}\text { Distance to nearest Golden } \\
\text { Eagle nest }\end{array}$ & & & & -12.280 & 0.027 & 0.166 \\
\hline $\begin{array}{l}\mathrm{df} \\
\mathrm{R}^{2} \text { adjusted }\end{array}$ & $\begin{array}{l}14 \\
0.443\end{array}$ & & & $\begin{array}{l}13 \\
0.804\end{array}$ & & \\
\hline
\end{tabular}

variation in number of breeding pairs per year but numbers remained relatively constant or even slightly increased over the study period. The average productivity of o.69 juveniles per breeding pair per year differs from that of Griffon Vulture populations elsewhere. Sarrazin et al. (1994) found a productivity of 0.82 for a successfully reintroduced Griffon Vulture population in the Causses, France, but this latter population probably thrived under favourable conditions and seemed unaffected by intra-specific competition (Sarrazin et al. 1994). Martínez et al. (1997) found a mean productivity of 0.5 for the breeding population inhabiting the gorges of the Riaza River; Spain. This variation in breeding success, between areas, could be explained by differences in food availability, intra-specific competition (density of breeding pairs), or climate. Moreover, large year-to-year variation has also been recorded for the Cape Vulture, with fledging success varying from $64-75 \%$ to $27-43 \%$ dependent on the year of study (Borello and Borello 2002). Nevertheless, reproductive rate does not seem to be the central demographic parameter influencing the population dynamics of Griffon Vultures. It is believed that species with a large body size, a low reproduction, and a long life expectancy depend heavily on high adult survival for their population success (Mertz 1971). This is partly in agreement with our results for the population in Riba-Côa. Estimates of mortality rates for adult- and sub-adult birds were as low as 0.04 and 0.045 and seem to be comparable to the annual mortality rate of 0.02 for adults found by Sarrazin et al. (1994), although the latter study was carried under favourable conditions for Griffon Vultures. Nevertheless, the sensitivity analyses showed, surprisingly, that the vulture population was most sensitive to changes in juvenile mortality. Egg and hatchling survival also seemed to have a great effect on the size of the population followed by the adult mortality. In agreement with Sarrazin et al. (1994) the period between incubation and becoming an immature seems to be a critical period for Griffon Vultures, and one that seriously affects the population size. The juvenile mortality rate calculated in this study seems to be high with $77 \%$ of all juveniles dying in their first year. In France, mortality rates for first year birds were low, $<30 \%$ (Sarrazin et al. 1994), but this study was carried out in a re-introduction programme using special protection measures. However, higher mortality rates have been found for juvenile Cape Vultures with 83\% (Piper et al. 1981), although Piper et al. (1999) confirmed that this latter mortality rate was probably overestimated, and re-estimated mortality for first year young, now based on colour rings, between $44 \%$ and $71 \%$, decreasing to $19-56 \%$ under supplemented feeding. Borello and Borello (2002) also reported high nestling mortality rates for Cape Vultures 
in which only $38 \%$ of all eggs laid produced fledged juveniles. It is impossible to identify the cause of death for juvenile Griffon Vultures in Riba-Côa, but we assume that high mortality is a consequence of their inexperience. Newly fledged Griffon Vultures often use flapping flight, which is energetically costly and may result in exhaustion, dehydration and starvation (Sarrazin et al. 1994). Griffon Vultures are partial migrants, with especially immature birds migrating annually (Mundy et al. 1992). This migratory behaviour could have influenced our assessment of juvenile mortality as it is possible that a number of immature birds migrated before our agestructure observations started. This would have resulted in an under-estimated immature population and consequently an over-estimate of juvenile mortality. Although the population structure seems plausible, with a satisfactory adult-juvenile ratio, monitoring the population more intensely and frequently (e.g. by using monitoring colour rings for population dynamics, or GPS tracking to determine home ranges), and for a longer period of time would presumably result in a more accurate population age structure.

Parra and Tellería (2004) showed that fluctuations in the number of Griffon Vulture breeding pairs were positively correlated with changes in livestock abundance, supporting a functional relationship between food availability and vulture abundance. Following this, we found that a $50 \%$ decrease in available food biomass resulted in a rapid decrease in vulture numbers of $11 \%$ over 5 years. Nevertheless, once food availability was restored, the population grew steadily but slowly back to its original size due to an increase in adult breeding birds. We should point out here that, when building the model, we assumed that breeding activity is restricted to adult birds only. However, sub-adults have been occasionally recorded breeding in many species of large raptors. This could be explained by reduced intra-specific competition when populations decrease, or by sub-adults being able to attain breeding condition when environmental factors are favourable (Newton 1979). This suggests that after a period with food scarcity the actual percentage of birds breeding could be higher than indicated by the model, resulting in a more rapid increase in vulture numbers.

According to our calculations, the Riba-Côa vulture population consumes an extremely high proportion $(80 \%)$ of the available biomass in the area $(25 \mathrm{~km}$ radius around each observation site). Although Arroyo and Garza (1995) showed that $70 \%$ of the Griffon Vulture foragerecords were made less than $25 \mathrm{~km}$ away from the corresponding colonies, it is possible that the vultures in the Riba-Côa area travel greater distances to find sufficient amount of food. In this context it is important to note that we assumed that $27-31 \%$ of the total carcass weight is consumed by Griffons, although Mundy et al. (1983) recorded values as high as 65\% (assuming that all carcasses are found and are eaten completely). It is therefore recommended to study the fraction of dead livestock that vultures can find, and the fraction of body mass that is actually consumed from the carcasses. Nevertheless, on our present calculations, this result could be a sign that food availability in the Riba-Côa area is currently limiting the growth of the population. More importantly, however, it seems that a small reduction in livestock biomass (e.g. active destruction of carcasses due to some epidemic disease) could have immediate negative effects on the vulture population size. This relationship was also found by Parra and Tellaría (2004) for Griffon Vultures in Spain. The creation of artificial feeding sites (vulture restaurants) in the area could relieve the vulture population (and other scavengers inhabiting the area) from this limitation and significantly increase their survival rates, especially of juvenile birds (Piper et al. 1999).

Habitat quality probably regulates raptor populations and determines the species' settlement pattern, such as also shown for Egyptian Vultures (Sarà and Di Vittorio 2003). The spatial distribution model showed that biomass of cattle, sheep and goats, distance to the nearest unpaved road, distance to nearest power line, distance to the nearest Bonelli's Eagle nest, and distance to the nearest Egyptian Vulture nest are the main factors determining the selection of a cliff as a nesting site. Food availability and human disturbance have also been correlated with population fluctuations in other studies or with other species (Cinereous Vulture: Poirazidis et al. 2004, Griffon Vulture: Xirouchakis and Mylonas 2005, multiple species: Thiollay 2006). 
The fact that numbers of breeding pairs increased with decreasing distance to the nearest power line (Table 5) can be explained by the high density of power lines throughout the study area, as it is highly suitable for hydroelectric energy production. Simultaneously, the steep cliffs and altitudinal differences are also favourable for Griffon Vultures, and therefore the relationship between power lines and Griffon Vulture distribution can be considered as an indirect, confounding effect, as they occur in similar areas. The presence of power lines does not seem to affect the distribution pattern of Griffon Vultures negatively in the Riba-Côa area. This is also demonstrated by one of the observation cliffs in the study area where a large number of breeding pairs occurred next to a hydro-electric dam. Moreover, only 6 birds per year are killed by collision with power lines in Portugal (Janss and Ferrer, 1999). The problem of electrocution by power lines cannot currently be assessed accurately for Griffon Vultures (Slotta-Bachmayr et al. 2004, see also Donázar et al. 2002a), although for other cliff breeding birds, especially Bonelli's Eagle, electrocution is one of the main causes of mortality in some regions as they use the power lines as perching sites for hunting (Janss and Ferrer, 1999). The number of breeding pairs of Griffon Vultures increased with increasing distance to the nearest unpaved road, which confirms that they have a preference for relatively undisturbed and inaccessible areas (Pain et al. 2003). Surprisingly, the vultures seem to be quite tolerant of human disturbance since one of the largest colonies is located next to a hydroelectric dam with roads and frequent visits by tourists. Despite this, we believe it is necessary that breeding areas are protected, to keep the level of disturbance as low as possible, as disturbances by recreation can be a problem at breeding sites (Slotta-Bachmayr et al. 2004).

Our results indicate that, in the Riba-Côa area, Griffon Vultures seem to nest near other cliff breeding raptors like Bonelli's Eagle and Egyptian Vulture. When the distance to the nearest other cliff breeding raptor nest increased, the number of Griffon Vulture breeding pairs decreased. This relationship was strongest with the Egyptian Vulture, which could be explained by the fact that the species have similar habitat requirements. In some cases the Egyptian Vultures were seen feeding on food leftovers from juvenile Griffons which lead us to believe that the Egyptian Vulture, to some extent, benefits from the presence of Griffon Vultures. However, prior research showed that an increase in Griffon Vulture abundance may negatively affect other cliff-nesting raptors, since their eyries are frequently taken over by Griffon Vultures (Donázar and Fernández 1990). This process has also been observed in Riba-Côa (A.E. Monteiro, pers. obs.); Griffon Vultures repeatedly occupied the nests of Bonelli's Eagles forcing the Bonelli's Eagle to settle elsewhere. Our results suggest that cliff breeding birds in Riba-Côa breed in close proximity, but their interspecific relationships are unknown.

Despite the endangered status of several cliff breeding raptors, there are considerable gaps in our knowledge concerning many aspects of their biology, limiting the implementation of adequate management plans. The results of this study provide useful empirical data regarding the population dynamics and spatial distribution of the Griffon Vulture population in Riba-Côa area. We conclude that the Griffon Vulture population is extremely sensitive to small variations in mortality rates, of juvenile birds especially. Although food availability is just one of several factors affecting the growth of these Griffon populations (Griffon Vultures: Sarrazin et al. 1994, Parra and Tellaría 2004, other species: Thiollay 2006) it currently appears to be important in both survival and spatial distribution of the Riba-Côa population. Therefore, future research should focus on categorizing the most important foraging areas that are used by the Griffon Vulture population in order to monitor and possibly safeguard their food supply. In addition, human disturbance should be kept to a minimum by protecting breeding areas, especially in an area like Riba-Côa where species such as the Egyptian Vulture, Bonelli's Eagle and Griffon Vulture breed so close to each other. The challenge is to combine spatial analyses (e.g. GarciaRipolles et al. 2005) with dynamic population models, in order to be able to understand the underlying causes behind differences in population development, and the spatiotemporal distribution of vultures. 


\section{Acknowledgements}

We are indebted to Ana Berliner from the Associação Transhumância e Natureza (ATN) for her support, guidance and hospitality. The census data were made available to us by the ATN and the Parque Natural do Douro Internacional (PNDI). Furthermore we would like to thank Jorge Amaral and Telmo Ramalho for their help in logistics; to Vicente Alcazar for supporting our observations in Spain; to Dr. Arend M.H. Brunsting for his help with the model in Stella, and to Dr. Sip E. van Wieren for assisting us in the calculations concerning food biomass. Funding for this research was provided by FONA, with special thanks to Prof. Dr. Jan H. Koeman and Dr. Henk Smit for their support and helpful tips, and two anonymous referees and the editor for their comments on an earlier version of the paper.

\section{References}

Arroyo, B. and Garza, V. (1995) Seguimiento radiotelemetrico del Buitre Leonado (Gyps fulvus) en el Parque de las Hoces del Rio Duratón (Segovia) [Tracking of Griffon Vulture (Gyps fulvus) using radiotelemetry in the Hoces del Rio Duratón Park (Segovia)]. Junta de Castilla y Léon: Consejeria del Medio Ambiente y Ordenación del Território.

BirdLife International (2007) Species factsheets: Accipitridae. Downloaded from http://www.birdlife.org on 21/6/2007.

Blanco, G., Martínez, F. and Traverso, J. M. (1997) Pair bond and age distribution of breeding Griffon Vultures Gyps fulvus in relation to reproductive status and geographic area in Spain. Ibis 139: 180-183.

Borello, W. D. and Borello, R. M. (2002) The breeding status and colony dynamics of Cape Vulture Gyps coprotheres in Botswana. Bird Conserv. Internat. 12: 79-97.

Bort, J., Errando, E. and Agueras, M. (1993) Evolución del Buitre Común (Gyps fulvus) en el país Valencià [Development of the Griffon Vulture (Gyps fulvus) in Valencià]. Inter Natura: Grup d'Estudi i protecció de les Rapaces (G.E.R.).

Cheylan, G. (1981) Introduction. Rapaces Mediterranéens 1: 3-5.

CNIG (2003) Aerial photographs, 1:10 ooo Lisbon: Centro Nacional de Informação Geográfica.

Donázar, J. A. and Fernández, C. (1990) Population trends of the Griffon Vulture (Gyps fulvus) in Northern Spain between 1969 and 1989 in relation to conservation measures. Biol. Conserv. 53: 83-91.
Donázar, J. A., Palacios, C. J., Gangoso, L., Ceballos, O., Gonzalez, M. J. and Hiraldo, F. (2002a) Conservation status and limiting factors in the endangered population of Egyptian vulture (Neophron percnopterus) in the Canary Islands. Biol. Conserv. 107: 89-97.

Donázar, J. A., Blanco, G. and Hiraldo, F. (2002b) Effects of forestry and other landuse practices on the conservation of cinereous vultures. Ecol. Appl. 12: 1445-1456.

Elosegi, I. (1989) Vautour fauve (Gyps fulvus), Gypaete barbu (Gypaetus barbatus) Percnoptere d'Egypte (Neophron percnopterus) Synthèse bibliographique et recherches [Griffon Vulture (Gyps fulvus), Bearded vulture (Gypaetus barbatus), Egyptian Vulture (Neophron percnopterus); Bibliographic synthesis and research]. Acta Biologica Montana. Serie documents de travail 3 .

Field, A. (2005) Discovering statistics using SPSS. London: SAGE.

Friedman, R. and Mundy, P. J. (1983) The use of 'restaurants' for the survival of vultures in South Africa. Pp. $345-355$ in S. R. Wilbur and J. A. Jackson, eds. Vulture biology and management. Berkeley: University of California Press.

Garcia-Ripolles, C., Lopez-Lopez, P., GarciaLopez, F., Aguilar, J. M. and Verdejo, J. (2005) Modelling nesting habitat preferences of Griffon Vulture Gyps fulvus in eastern Iberian Peninsula. Ardeola 52: 287-304.

Gavashelishvili, A., McGrady, M. J. and Javakhishvili, Z. (2006) Planning the 
conservation of the breeding population of cinereous vultures Aegypius monachus in the Republic of Georgia. Oryx 40: 76-83.

Green, R. E. (2006) Decline of vultures in Asia. Science 311: 1378-1378.

Green, R. E., Taggart, M. A., Das, D., Pain, D. J., Kumar, C. S., Cunningham, A. A. and Cuthbert, R. (2006) Collapse of Asian vulture populations: risk of mortality from residues of the veterinary drug diclofenac in carcasses of treated cattle. J. Appl. Ecol. 43: 949-956.

IGEOE (2000) Topographic maps, 1:25 ooo, serie M888 Lisbon: Instituto Geográfrico do Exército.

Janss, G. F. E. and Ferrer, M. (1999) Avian electrocution on power poles: European experiences. Pp. 145-164 in M. Ferrer and G. F. E. Janss, eds. Birds and power lines: Collision, electrocution and breeding. Madrid: Quercus.

Komen, J. (1991) Energy requirements of nestling Cape Vultures. Condor 93: 153-158.

Martinez, F., Rodriguez, R. F. and Blanco, G. (1997) Effects of monitoring frequency on estimates of abundance, age distribution, and productivity of colonial Griffon vultures. J. Field Ornithol. 68: 392-399.

Mendelssohn, H. and Leshem, Y. (1983) Observations on reproduction and growth of Old World vultures. Pp. 214-24I in S. R. Wilbur and J. A. Jackson, eds. Vulture biology and management. Berkeley: University of California Press.

Mertz, D. B. (1971) The mathematical demography of the California Condor population. Am. Nat. 105: 437-453.

Monadjem, A. and Garcelon, D. K. (2005) Nesting distribution of vultures in relation to land use in Swaziland. Biodiv. and Conserv. 14: 2079-2093.

Moran-Lopez, R., Guzman, J. M. S., Borrego, E. C. and Sanchez, A. V. (2006) Nest-site selection of endangered cinereous vulture (Aegypius monachus) populations affected by anthropogenic disturbance: present and future conservation implications. Anim. Conserv. 9: 29-37.

Mundy, P., Morris, A. and Haxen, C. M. (1983) The proportion of an impala edible to vultures. Afr. J. Ecol. 21: 75-76.
Mundy, P., Butchart, D., Ledger, J. and Piper, S. (1992) The vultures of Africa. London: Academic Press.

Newton, I. (1979) Population ecology of raptors. London: T. \& A.D. Poyser.

Newton, S. F. and Newton, A. V. (1996) Breeding biology and seasonal abundance of Lappet-faced Vultures (Torgos tracheliotus) in western Saudi Arabia. Ibis 138: $675-683$.

Pain, D. J., Cunningham, A. A., Donald, P. F., Duckworth, J. W., Houston, D. C., Katzner, T., Parry-Jones, J., Poole, C., Prakash, V., Round, P. and Timmins, R. (2003) Causes and effects of temporospatial declines of Gyps Vultures in Asia. Conserv. Biol. 17: 661-671.

Parra, J. and Tellaría, J. L. (2004) The increase in the Spanish population of Griffon Vulture Gyps fulvus during 1989-1999: effects of food and nest site availability. Bird Conserv. Internat. 14: 33-41.

Piper, S. E., Boshoff, A. F. and Scott, H. A. (1999) Modelling survival rates in the Cape Griffon Gyps coprotheres, with emphasis on the effects of supplementary feeding. Bird Study 46 (Suppl): S230-238.

Piper, S. E., Mundy, P. J. and Ledger, J. A. (1981) Estimates of survival in the Cape Vulture, Gyps coprotheres. J. Anim. Ecol. 50: $815-825$.

Poirazidis, K., Goutner, V., Skartsi, T. and Stamou, G. (2004) Modelling nesting habitat as a conservation tool for the Eurasian black vulture (Aegypius monachus) in Dadia nature reserve, northeastern Greece. Biol. Conserv. 118: $235-248$.

Ruxton, G. D. and Houston, D. C. (2002) Modelling the energy budget of a colonial bird of prey, the Ruppell's griffon vulture, and consequences for its breeding ecology. Afr. J. Ecol. 40: 260-266.

Sarà, M. and Di Vittorio, M. (2003) Factors influencing the distribution, abundance and nest-site selection of an endangered Egyptian vulture (Neophron percnopterus) population in Sicily. Anim. Conserv. 6: 317-328.

Sarrazin, F., Bagnolini, C., Pinna, J. L., Danchin, E. and Clobert, J. L. (1994) High survival estimates of griffon vultures 
(Gyps fulvus fulvus) in a reintroduced population. Auk 111: 853-862.

Slotta-Bachmayr, L., Bögel, R. and Camina Cardinal, A. (2004) The Griffon Vulture (Gyps fulvus fulvus) in Europe and the Mediterranean: Status report and action plan. East European / Mediterranean Griffon Vulture Working Group.

Thiollay, J. M. (2006) The decline of raptors in West Africa: long-term assessment and the role of protected areas. Ibis 148: 240-254.

Tucker, G. M. and Heath, M. F. (1994) Birds in Europe: their conservation status. Birdlife Conservation Series $\mathrm{N}^{\circ} 3$. Cambridge, UK: Birdlife International.

Xirouchakis, S. M. and Mylonas, M. (2005) Selection of breeding cliffs by Griffon Vultures Gyps fulvus in Crete (Greece). Acta Ornit. 40: 155-161.

FLORIS VAN BEEST, LOES VAN DEN BREMER, W. F. DE BOER*, IGNAS M. A. HEITKÖNIG

Resource Ecology Group, Wageningen University, Postbus 47, 6400 AA Wageningen, The Netherlands.

ANTÓNIO E. MONTEIRO

Parque Natural do Douro Internacional, Rua de St. Marinha 4, 5200 Mogadouro, Portugal.

*Author for correspondence.e-mail: fred.deboer@wur.nl

Received 9 February 2007; revision accepted 10 July 2007 